\title{
ONTO-PDM: product-driven ONTOlogy for Product Data Management interoperability within manufacturing process environment
}

\author{
Panetto H. ${ }^{1 *}$, Dassisti M. ${ }^{2}$, Tursi A. ${ }^{1,2}$ \\ ${ }^{1}$ Centre de Recherche en Automatique de Nancy (CRAN - UMR 7039), University of Lorraine, \\ CNRS, France \\ herve.panetto@cran.uhp-nancy.fr, angelatursi@gmail.com \\ ${ }^{2}$ Dipartimento di Ingegneria Meccanica e Gestionale, Politecnico di Bari, Italy \\ m.dassisti@poliba.it
}

\begin{abstract}
This paper proposes an approach for facilitating systems interoperability in a manufacturing environment. It is based on the postulate that an ontological model of a product may be considered as a facilitator for interoperating all application software that share information during the physical product lifecycle. The number of applications involved in manufacturing enterprises may in fact refer to the knowledge that must be embedded in it, appropriately storing all its technical data based on a common model. Standardisation initiatives (ISO and IEC) try to answer the problem of managing heterogeneous information scattered within organizations, by formalising the knowledge related to product technical data. The matter of this approach is to formalise all those technical data and concepts contributing to the definition of a Product Ontology, embedded into the product itself and making it interoperable with applications, thus minimising loss of semantics.
\end{abstract}

Keywords: Enterprise Integration and Networking, Interoperability, Product Data Management, Ontology, IEC 62264, ISO 10303

\section{INTRODUCTION}

Managing distributed and delocalised production is one of the strongest issues to address in the present era of market globalisation: heterogeneous enterprise applications, either at business or at manufacturing levels, either inside a single enterprise or among networked enterprises, need to share information. Information management thus has become a major driver for management and product development in networked enterprises.

Product/process information is usually stored, processed and communicated in different ways by ICT applications, mainly depending on the scopes from which they have been collected and used: misunderstandings or loss of information might occur in these processes. It is not infrequent to find information scattered within the same organization: in the applications used to manage technical * Corresponding author: Prof. Hervé Panetto, CRAN, Campus Scientifique, BP 70239, F-54506 Vandoeuvreles-Nancy, France. herve.panetto@cran.uhp-nancy.fr, Phone: +33 383684426, Fax: +33 383684459 
data (e.g.: Product Data Management systems (PDM)), or in the applications that manage business information (e.g.: Enterprise Resource Planning (ERP)) or, finally, in the applications that manage manufacturing information (e.g.: Manufacturing Execution Systems (MES)).

Sharing product information is a prerequisite for integration between enterprises/systems that participate into an organization. However, most of the stakeholders have different business experience and business domains, interoperability of information among enterprises should be guaranteed in order that enterprises collaborate with other participants for integration in the value chain [1].

This "Babel-tower effect", caused by the heterogeneity or multi-view perspective of information, of their domains and their users, may lead applications systems to fail their local objective: this is a widely recognised problem of management of heterogeneous information, usually falling within the umbrella of interoperability problems [2].

Some attempts [3] have been made on this subject taking into account the definition of product families. They are interesting for our purpose, since they focus on the product features for finding commonalities in such families.

To overcome such class of problems, common product conceptual models to be shared within an organization have been introduced [4], i.e. managing heterogeneous information is only possible whenever common information-models are available, in the different phases of product lifecycle (design, manufacturing, sales, use and disposal). In the end, this means to let different operators and applications sharing a common ontology, consistent enough to be independent of the specific application domain and related implementations, as well as on the ICT technology available. More technically, the above mentioned interoperability problem is not only a matter of computer technology (related to concrete syntax) but also a semantic problem to be faced, which is related to conceptual issues. For the sake of clarity, based on the definition of Guarino [5], a conceptual model is defined as an abstraction from a given real system to provide formal meaning in any given domain.

This paper discusses the problem of management of heterogeneous information by conceptualising, formalising, building and explaining the rationale of a common product ontology developed to this purpose [6]. The next section details a literature review about related work on product ontology definition and use. This state-of-the-art shows that the existing work in this domain is not taking into account the existing standards developed for modelling product technical features. We will then introduce the two standards that are the basis of our knowledge enactment in this domain. We will conceptualize and then formally merge the knowledge embedded into the previous standards in order to propose a Product (top-domain) Ontology (named ONTO-“DM) as a common core model 
for applications interoperability in manufacturing process environment. A case study will validate our proposed ontology, instantiated to a B2M (Business to Manufacturing) application involving an ERP and a MES enterprise applications. We will conclude our paper with some future work and open issues.

\section{STATE OF THE ART ON PRODUCT ONTOLOGIES FOR INTEROPERABILITY}

The present section focuses on scientific efforts devoted so far relevant to the problem of semantic interoperability of product information [7]. No mention will be made on the huge mass of scientific works available on semantic web and related applications [8].

Yoo and Kim [9] present a Web-based knowledge management system for facilitating seamless sharing of product data among application systems in virtual enterprises. The authors claim the needs for standardised contents on product information and knowledge in order to avoid misunderstandings and mismatching: different terminologies can be in fact used for the same concept. They adopt an ontology for disambiguating such a potential inefficiencies. They thus mostly refer to STEP as a reference standard for their product models, by designing appropriate interfaces between different storage systems. No specific semantic approach is provided in their work, but only a syntactic approach. Advanced research activities in this area are instead oriented towards the use of ontologies as a foundation for the "Semantic Web" [10]. Vegetti et al. [11] propose an interesting approach for modelling product data in their ontology called Product ONTOlogy (PRONTO), which intends to provide a consensual knowledge model in the product modelling domain that can be used by all the stakeholders of extended supply chains, involving industrial organizations. PRONTO presents concepts involved in the product modelling domain that are primarily related to the product structure. However, even if PRONTO shares the same scope as ONTO-PDM, it does not refer to any existing standards developed to model the product structure, processes and features.

Different modelling languages are adopted to represent different product information, for example EXPRESS for geometry as seen in STEP, and UML for beyond geometry information as defined in Core Product Model (CPM) [12]. This last approach proposed the idea of an open, non-proprietary, generic, extensible, and independent of any one product development process by an appropriate modelling process, in line with the approach here proposed. A translation from EXPRESS to OWL enabling translation of STEP schema defined in EXPRESS to OWL is provided in [10], thus providing a semantically enriched model, called OntoSTEP that can easily be integrated with OWL ontologies[13]. The development of OntoSTEP requires the conversion of EXPRESS schemas to OWL-DL, and the classification of EXPRESS instances to OWL individuals [14]. However, 
OntoSTEP, as a translation of STEP ARM (Application Reference Models), is not a conceptual view of products but a reference (not implementable) view of product data models. The main concerns with such models is that they are not only representing semantic information related to product features but also structural data that do not bring any semantics and is used for future implementation. For example, from a semantic point of view, concepts identifiers do not geneally embed any semantics related to the product models and should then be avoided in an ontological semantic model.

An effort of significant relevance is the development of Product Ontology at the National Institute of Standards and Technology (NIST), PSL (Process Specification Language) [15], defines a neutral representation for interoperability of information relevant to manufacturing processes. It considers the representation of process data used throughout the life cycle of a product and an ontology has been developed for facilitating the exchange of information among various manufacturing process related software. Patil et al. [16] propose an ontology-based framework to enable the semantic interoperability across different application domains. The authors stress on the need to enable semantic interoperability using a common format representing product-specific information, there called as Product Semantic Representation Language (PSRL). They claim the requirements of application independency, expressiveness and unambiguity are satisfied by their PSRL, representing a building block for building any kind of ontology for an intuitive and comprehensive representation of product information. As stated by the same authors, their work is a subset of the more general OWL language here adopted; at the same time, their semantic mapping assumes the existence of exactly equivalent interpretations, which is not always the case. PRSL uses the Core Product Model (CPM) as a basis for the development of a formal representation of product information [17]. The Core Product Model presents a generic product representation scheme for the entire product development activity; initially developed at NIST for a number of in-house research projects. An extension to this model is OAM (Open Assembly Model) [18], which includes assembly, tolerance and propagation, kinematics and engineering analysis. The OAM represents the function, form, and behaviour of assemblies and defines both a system level conceptual model and the associated hierarchical relationships [18]. Further extensions of these models are the DesignAnalysis Integration model (DAIM) and the Product Family Evolution Model (PFEM) that are abstract models with general semantics, including also specific semantics about a particular domain to be embedded within the usage of the models for that domain [19]. These efforts show the importance of generalising product concepts toward a more comprehensive semantic, such as standards do, to easily share knowledge related to products or product families design. The only drawback is to be a ex-novo effort, which has the main advantage of customisation to specific 
applications' culture (e.g. design, manufacturing, etc.) but has a main risk of being a standalone effort, while adoption of widely diffused standards for conceptualisation and programming languages to express concepts can turn to be very effective and also, if the process self-grows, effective. This is the path here proposed.

In [20] and [21], approaches toward the development of a product ontology and semantic mapping using first-order logic are presented. These efforts propose the development of a shared ontology. In [22][23], an ontological approach is proposed to enable the exchange of features between application CAD/CAPP software. It uses the knowledge interchange format (KIF) [24] to model participating ontologies and to create a common intermediate ontology. Rules are manually specified to enable mapping of concepts from one domain to another. These approaches are focusing on the semantics of technical vocabulary for specific domains and it is difficult to generalize them to different contexts.

Some efforts in the same direction are made in the PROMISE-PLM European project [25], that implemented the work of Terzi [26][27] with the objective of developing a new generation of product information tracking and flow management system, with a particular focus on use, service and maintenance phases of the product lifecycle. As a result of this project, in the PROMISE FP6 project (www.promise.no), a first version of an ontology model of Product Data and Knowledge Management Semantic Object Model (SOM) has been developed [28]. This approach is very close to our philosophy, since it implements into an ontology features from an existing PLM model using OWL-DL: it is, on the other hand, only a small part of our proposed model where product standards are used as basis for product modelling, achieving both an efficient description of the product as it is designed from manufacturer and a functional structure for storing data of the product's lifecycle (as discussed in [29]).

Another interesting project of the European Community is PABADIS'PROMISE, called P2 project (www.pabadis-promise.org), which stipulates an innovative control and networking architecture across the three levels of automation (ERP level, MES level, Field Control level) [30].

In the last years, the research is increasingly focusing on the study of ontology-based approaches for product lifecycles interoperability in extended enterprise: Bock et al. [31] describe an example of a product modelling language to support collaborative design, combining the benefits of ontology with expanded capabilities in conventional product modelling language. The authors address an interesting claim to generalization as a technique for interoperating product models, and at the same time the problems tied to the adoption of ontological product modelling by ontology languages, because these are not specific to engineering. Chen et al.[32] develop a novel mechanism for integrating ontology-based product lifecycle knowledge to effectively integrate the heterogeneous 
product knowledge distributed among different enterprises during a product's lifecycle. Jiang et al [33] present an ontology-based framework of knowledge integration under the collaborative business process in networked collaborative manufacturing environment, providing comprehensive concepts and knowledge connections to effectively integrate an individual enterprise's knowledge integration. These authors move toward the solution in the path of a brand-new approach that can be risky with respect to our choice of referring to standard solutions and set of knowledge.

Lin et al [34] suggest the use of OWL language with SWRL rules to develop manufacturing ontologies using both software engineering and Semantic Web paradigms. A multi-layered productmodelling framework that enables stakeholders to define their product-specific models and relates product-specific models to physical or simulated instances is presented in [35]. These works are focused on languages for semantic representation.

In [36], the authors deal with semantic heterogeneity by proposing the use of ontologies as metadata descriptions of the information sources as a possible approach for providing an integrated view of multiple parts libraries. They use meta-concepts with which the ontology developers describe the domain concepts of parts libraries to ensure that the mismatches between parts library ontologies are confined to manageable mismatches which a software program can resolve automatically. This work may be considered as complementary of our work in the sense that our ONTO-PDM product ontology may be used as a top-domain ontology, but at a higher level than the shared ontology proposed by these authors. [37] introduce a general manufacturing system engineering (MSE) knowledge representation scheme, called an MSE ontology model, for facilitating communication and information exchange in inter-enterprise, multi-disciplinary engineering design teams, encoded in the standard semantic web language. It provides access by common mediated meta-models across all engineering design teams through semantic matching. [38][39] propose a methodology for building a semantically annotated multi-faceted ontology for product family modelling that is able to automatically suggest semantically-related annotations based on the design and manufacturing repository. This work concerns a deeper level of detail even though it is susceptible to be used as a general methodology to build an application ontology.

[40] have proposed a formal set of ontologies for classifying analysis modelling knowledge for facilitating knowledge exchange and reuse, adaptability, and interoperability of analysis models in engineering tasks, and [41] suggested a methodology to allow researchers and industry to create ontologies for their particular purpose and a thesaurus for the terms within the ontology. However, none of these works are focusing on product features that are the core knowledge shared by any product lifecycle management (PLM) systems. 
Most of these works related to Product Ontology have the same final objective; despite that they share, more or less, the same scope as our work, most of the time in a different application domain. They have been either related to geometry data or they have focused only on generic product information (PRONTO and PSL) or they have focused their study in the technology and the implementation [42] rather than to the conceptual view of product data exchange (such as PROMISE-PLM and PABADIS'PROMISE projects). In this paper, we are focusing on conceptualising, merging and reusing knowledge embedded into existing standards for product technical data (ISO 10303 [43] ) and ERP/MES data (IEC 62264 [44]) to formalise a Product Ontology (ONTO-PDM) for enterprise applications interoperability, centred to the product, the main object shared by all stakeholders in an enterprise.

\section{PROBLEM STATEMENT}

Each enterprise application within a factory uses an information repository, which refers to a Reference Information Model (RIM). A RIM specifies the structure as well as embeds the semantics of the information treated, in relation to the scope of the application to which it is devoted. This reference model may be either ad-hoc, thus developed specifically for and by any enterprise application, or standard to assure a consensus process to take place among various key actors in the application domain.

Each enterprise application retrieves information from its repositories, according to the specific need during its operations and problems may occur in the case of use of different repositories: provided that there is not an univocal way to express the same information, the translation required may lead to significant loss of information, due to several causes and this may have impact on its effectiveness. Such problems, thus, occur when there is a need to exchange information between enterprise applications: problems of misunderstanding among heterogeneous systems, due to different points of view - dependent on the scope of each application - or worst misunderstanding may lead to loss of information semantics [45].

The purpose of our methodology is to provide insights for generalising a knowledge representation process to feed concepts into an ontological model. To achieve this research objective, we are proposing two main steps: the first one consists in conceptualising existing standards, related to product technical data modelling for the definition of products information, providing a "productcentric" information model to represent knowledge and concepts. These concepts can be processed by several enterprise applications within a manufacturing environment: the standards considered for this purpose were ISO 10303 and IEC 62264. The second step is then to formalize this proposed 
"product-centric" information model in terms of a Product Ontology, thus including business rules, to express and share product knowledge among systems [45].

The final result of these steps is a prototype of a Product Ontology which, based on standard modelling concepts, intend to provide an interoperability solution between product views and enterprise applications that will manage them, formalising knowledge and skill around products[46].

The integrated management of all the information regarding the product and its manufacturing is one of the more complex questions that characterize today's environment, defining a sort of shift paradigm so-called "product-centric" or product-driven interoperability [47] [48]. In such a vision, the product itself becomes the medium of the data set, instantiating a kind of active product [49], able to interoperate in its environment, exchanging information (which is considered to be into the product itself) in real-time with different resources.

\section{CONCEPTUALISATION OF STANDARDS FOR THE PRODUCT ONTOLOGY}

An ontology is an explicit specification of a shared conceptualization [50] Erreur ! Source du renvoi introuvable.which allows the representation of domain's knowledge, to express it and to share it. It allows the formalization of the semantics of objects, and to identify concepts and their constraints regarding the engineering domain that uses them. An ontology is agreed upon by developers of different applications or systems per se, willing to integrate in it concepts and properties specific to their applications, in order to find correspondences between application models and to facilitate a common "grounding".

Standards are founded on the same principles; a standard is built by sharing the knowledge of groups of experts finding an agreement on a specific domain. Some interesting standardisation initiatives have tried to formalise the knowledge related to products' technical data, in order to solve the management problem of heterogeneous information. These are related to Product Data Management at the business and at the manufacturing level of enterprises (B2M); in this sense these can be considered as a sort of "Product Ontology".

We consider the models specified in standards related to product and interoperability as a good starting point of knowledge for our purpose of conceptualising a common reference-information model, for facilitating information exchange amongst applications adopted for manufacturing that use different product views. These models are intended to formalise an embedded Product Ontology that may be get refined during the product lifecycle by the virtue of using it to communicate with the applications. 
The standard chosen for this scope are the ISO 10303 [43], and in particular STEP PDM, and the IEC 62264 [44]. STEP PDM Schema deals with typical product-related information including geometry, engineering drawings, project plans, part files, assembly diagrams, product specifications, numerical control machine-tool programs, analysis results, correspondence, and bills of material, engineering change orders, and many more. IEC 62264, on the other hand, specifies a set of reference models for information exchange between business applications and manufacturing control applications.

These standards are commonly accepted to allow information exchange between ERP, CAD, PDM and MES applications, providing sort of application-driven interoperability architecture (Figure 1).

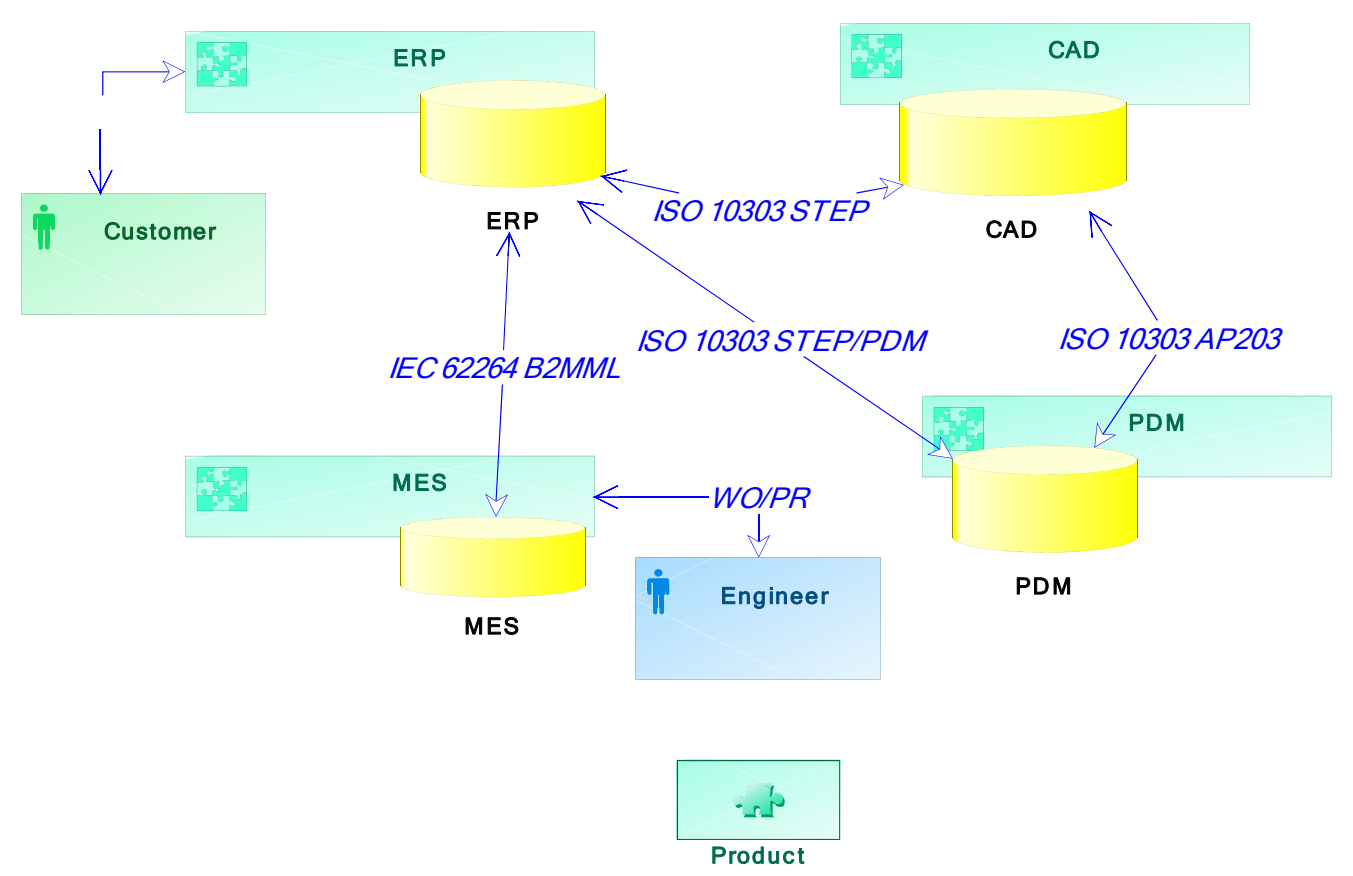

Figure 1 - ISO 10303 and IEC 62264 standards within a manufacturing enterprise

Such standards have been developed and proposed to provide means and technology to integrate different business-management software among business partners. It is evident that the existing standardisation initiatives share a common objective: trying to answer the information interoperability problem by formalising the knowledge related to products technical data along its lifecycle. Currently, standard models are used to allow the exchange of information between an ERP, PDM and MES under an application-driven frame. Nevertheless the approach contained in standards is rather prescriptive, in the sense that it forces users to translate information from generic concepts to more pragmatic and ad-hoc ones.

To ensure enterprise level interoperability, on the other hand, it is absolutely critical that information standards are harmonized as there are overlapping and dissimilar standards are available [51Erreur! Source du renvoi introuvable.]: a special care should be devoted to 
overcome this problem. The aim of this paper is to contribute to the problems of product/process information interoperability within manufacturing systems by:

- providing a new approach to solve interoperability problems, founded on existing standardization initiatives, based on an appropriate formalisation and harmonisation of the knowledge and the skill embedded in products (and the related semantics of concepts);

- defining a Product Ontology potentially capable to solve interoperability problems between different enterprise applications;

\subsection{Models behind ISO 10303 - STEP PDM}

STEP is based on a modular and re-configurability structure, which uses Application Protocols (APs) to specify the representation of product information for one or more applications. Application Protocols are sub-sets of STEP, focused on specific issues or specific industrial sectors, which break the entire STEP standard into easily manageable views of quick implementation. STEP initiative adopts a strategy of specification into industrial context (e.g. APs for product design, for mechanical and electrical engineering, for sheet metal manufacturing, for product assembly, for automotive industry). Each AP is applicable to one or more life cycle stages of a particular product class.

We focus on STEP PDM (Product Data Management) schema, which is a reference information model for the exchange of a central, common subset of the data being managed within a PDM system. It represents the intersection of requirements and data structures from a range of STEP Application Protocols, all generally within the domains of design and development of discrete electro/mechanical parts and assemblies.

A significant solution for PDM (Product Data Management) data exchange is the Unified PDM Schema, which is a basic specification for the exchange of administrative product definition data. It has been created by unifying all PDM data between all existing STEP Application Protocols, and allows the exchange of information that is stored in PDM systems. This information typically forms the metadata for any product. In order to deal with the increasing demands on product models exchange, the standard has specified a set of STEP reusable modules related to PDM. These modules are now published as technical specifications (TS) and concern all related information attached or describing products technical data such as product structure, configuration control, persons and organisations, etc. PDM systems maintain a single copy of the product master data in a secure vault; the data are then distributed to those departments requiring them: modified, updated design data are then resaved in the vault. The PDM Schema ensures that the information describing 
product design, manufacturing and life cycle support is defined only once; STEP data integration eliminates redundancy and the problems caused by redundant information.

We here provide an example of the result of conceptualisation of the standard that enact the semantics of product data within STEP PDM, by considering a bill of material. The bill of material $(\mathrm{BOM})$ is one of the crucial product technical data in the production management domain as well as in the information technology that supports itErreur! Source du renvoi introuvable.: the BOM represents the base issue of integrating product design system with production planning system [52]. The STEP PDM Schema supports hierarchical product structures representing assemblies and the constituents of those assemblies: this product structure corresponds to the traditional engineering and the manufacturing bill-of-material corresponds to the hierarchical decomposed parts list.

Part of the STEP PDM models conceptualised using the UML class diagram language of the assembly structure is represented in Figure 2, the original EXPRESS-G representation of one concept in Figure 3 and its original translation in EXPRESS is depicted in Figure 4.

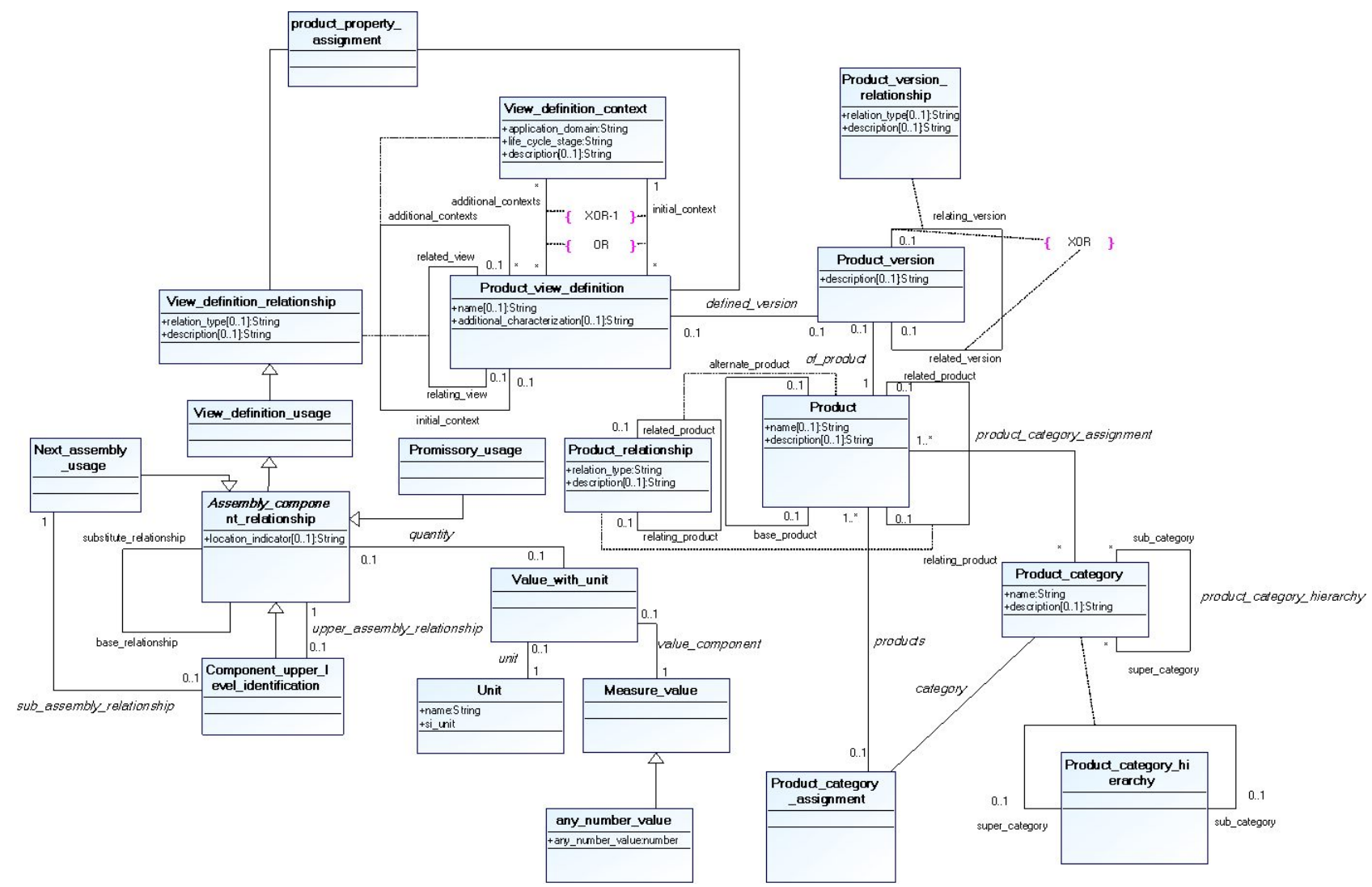

Figure 2 - Assembly structure module conceptualized in UML 
The Assembly_component_relationship (see Figure 2) is established between two instances of Product_view_definition: the relating view of Product_version of assembly and the related one of the Product_version which plays the role of component. A Product_view_definition is a collector of the properties that characterize the Product_version in the initial_context and possibly additional_contexts. A Product_version is a revision or a collector of the definitions of the revision of Product.

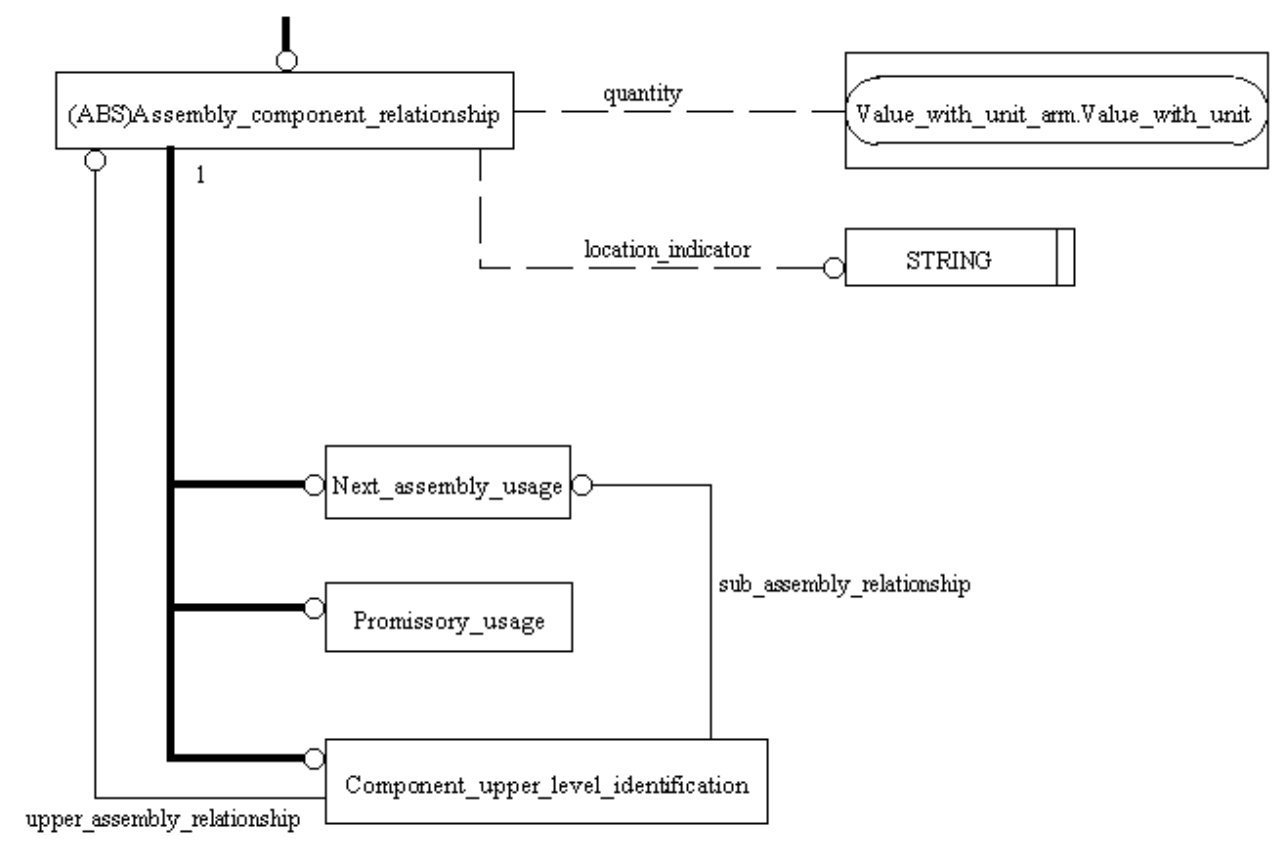

Figure 3 - Assembly structure in EXPRESS-G

The Assembly_component_relationship class (Figure 3 and Figure 4) represents the general relationship between two parts, one a definition of a component and the other a definition of the parent assembly. This entity is typically instantiated as the subtype Next_assembly_usage, which represents an unique individual occurrence of the component as used within the parent assembly. The subtype Promissory_usage, instead, represents the usage occurrence of a component within a higher-level assembly that is not the immediate parent. The subtype Component_upper_level_identification identifies a component of an assembly with respect to an upper level in the assembly structure [45]. 


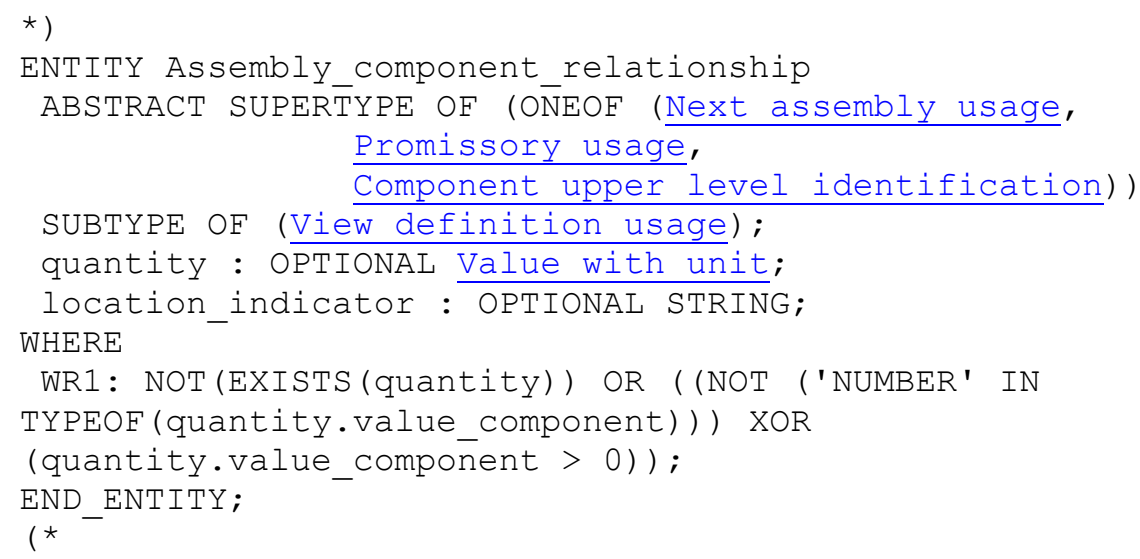

\section{Figure 4 - Assembly structure in EXPRESS}

\subsection{Models behind IEC 62264}

The IEC 62264 standard concern the information related to the interface between plant production scheduling, operation management and plant floor coordination. To take into account the various exchanged information, through the product representation, the IEC 62264 standard defines a set of eight sub-models that specify all concepts for enterprise-control integration. These can be appropriately adopted to setup the Product Ontology for interoperability. Our conceptualisation is based on one interpretation of the eight sub-models. Here below, we provide the set of statements, derived from the standard, used to form this interpretation:

Product Definition: the product definition model contains information shared between production rules, bill-of-material, and bill-of-resources. It also contains a listing of the exchanged information about a product. The information is used in a set of product segments that are the values needed to quantify a segment for a specific product. A product segment makes a reference to a process segment. It is related to a specific product, while a process segment is product independent. The collection of product segments for a given product specifies the sequence and ordering of segments required to manufacture a product in sufficient detail for production planning and scheduling. The corresponding production rule presents the additional detail required for actual production.

Material: the material model defines the actual materials, material definitions, and information about classes of material. Material information includes the inventory of raw, finished, and intermediate materials. Material classes are defined to organise materials. A Material definition is a means to describe goods with similar characteristics for purposes of scheduling and planning. 
Equipment: the equipment model contains the information about specific equipment, the classes of equipment, equipment capability tests, and maintenance information associated with equipment.

Personnel: the personnel model contains the information about specific personnel, classes of personnel, and qualifications of personnel.

Process Segment: the process segment model contains process segments that list the classes of personnel, equipment, and material needed, and/or it may present specific resources, such as specific equipment needed. A process segment may list the quantity of the resource needed. A process segment is related to a product segment that can occur during production, as presented in the product definition model.

Production Schedule: a request for production is listed as a production schedule. A production schedule is made up of one or more production requests. A request for production for a single product identified by a production rule is shown as a production request. A production request contains the information required by manufacturing to fulfil scheduled production. This may be a subset of the business production order information, or it may contain additional information not normally used by the business system. A production request may identify or reference the associated production rule. A production request also contains at least one segment requirement, even if it spans all production of the product.

Production Capability: the production capability information is the collection of information about all resources for production for selected times. This is made up of information about equipment, material, personnel, and process segments. It describes the names, terms, statuses, and quantities of which the manufacturing control system has knowledge. The production capability information contains the vocabulary for capacity scheduling and maintenance information.

Production Performance: the performance of the requested manufacturing requests is listed as production performance. Production performance is a collection of production responses. The responses from manufacturing that are associated with a production request is used as production responses. There may be one or more production responses for a single production request if the production facility needs to split the production request into smaller elements of work. A production result may include the status of the request, such as the percentage complete, a finished status, or an aborted status. 
IEC 62264 do not use UML representation for displaying each "class" of information and its relations with other classes. Figure 5 depicts, using UML class diagram, a conceptualisation of the IEC62264 Material Model, which is a part of the Product Ontology here proposed.

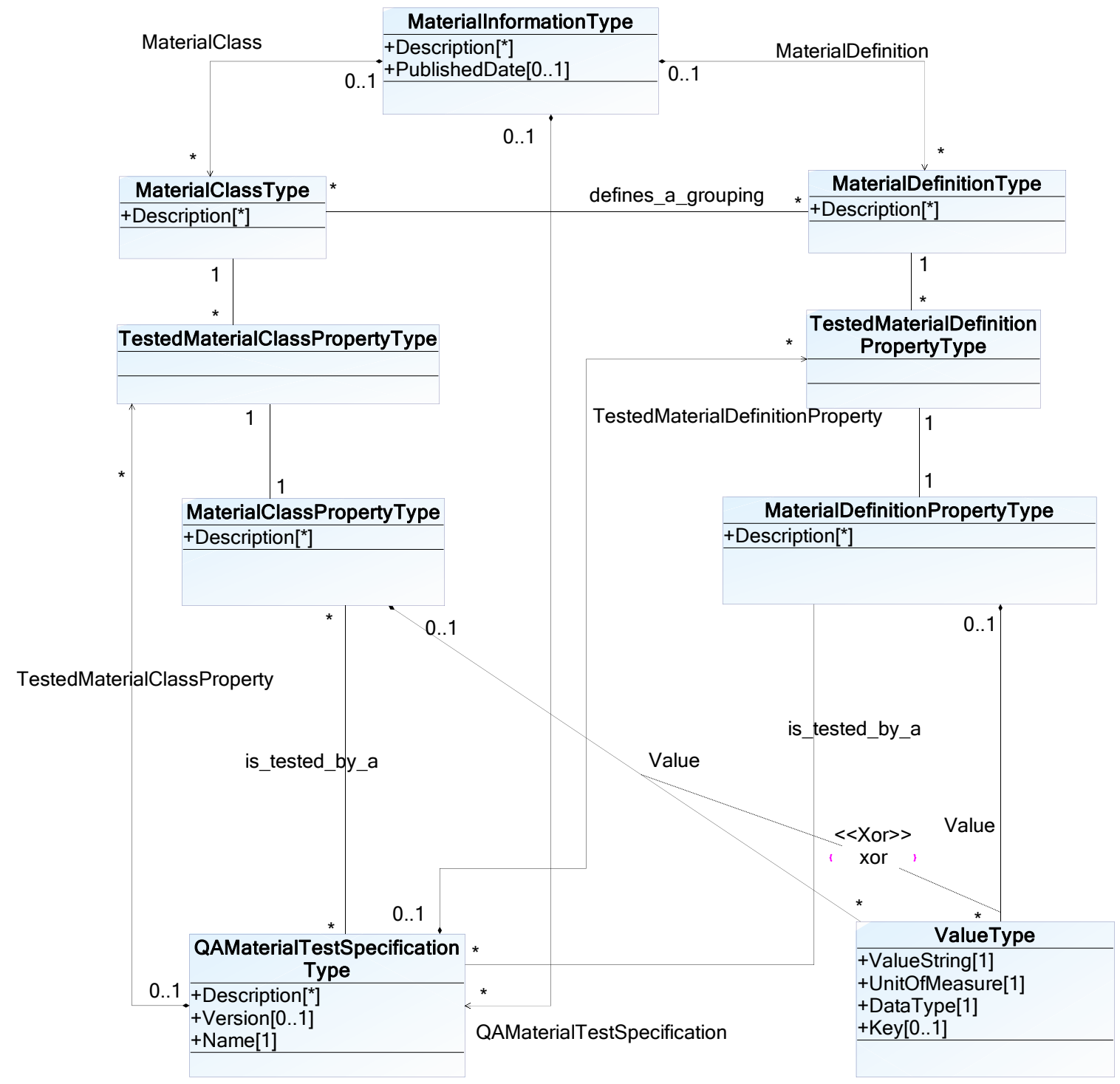

Figure 5 - Conceptualised “Material Model” from IEC 62264

\section{THE PRODUCT ONTOLOGY}

Starting from the above conceptual views of the standards, a product may be considered as truly interoperable per se, as far as it implicitly embeds all of its technical data and information. This point-of-view reverses the common approach adopted to solve interoperability problems: provided this information is structured in a common formal model, including domain rules, it can provide mappings from and to the enterprise applications, either inside a single enterprise or between networked enterprises, throughout all its life cycle. 
The main objective of our research activities is to define and possibly formalize the information model necessary to the product to become interoperable per se with the many applications involved in manufacturing enterprises and, as far as it embeds knowledge about itself, storing all its technical data, it will be able to act as a common source of understanding between enterprises applications. This results then to a so-called product-centric interoperability (Figure 6).

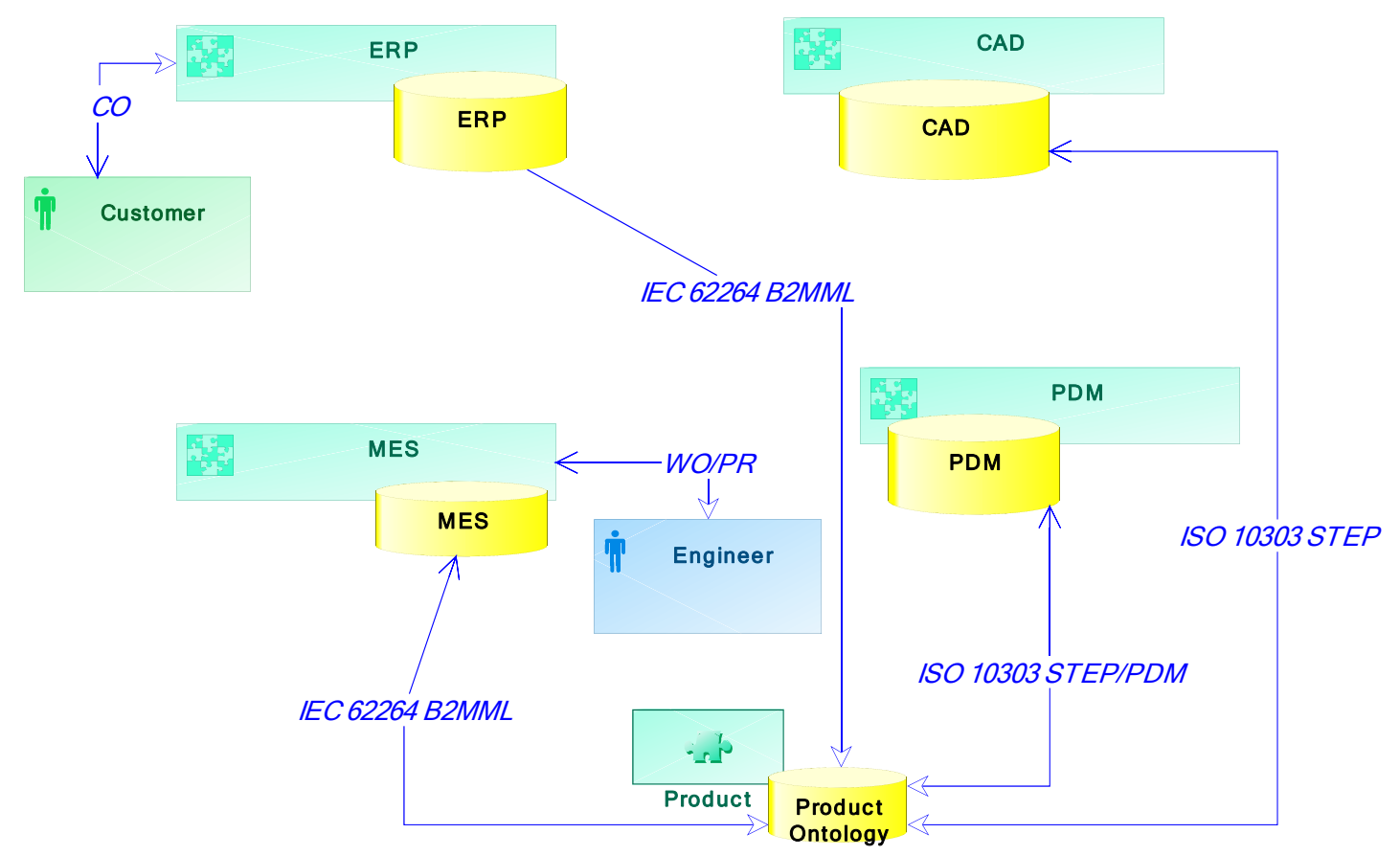

\section{Figure 6 - Product-centric interoperability architecture}

\subsection{Formalization approach through First-Order-Logic}

The first step of our approach is based on a syntactical analysis, to compare the instances defined in both standard models and then comparing properties of the shared objects, based on semantic analysis. This approach may suffer of subjectivity and of being dependent on human interpretation; but it is necessary to understand the semantic of models information from standards. The mapping between selected standards was performed to verify and to check if they represent the same information. This has been done by instantiating the IEC 62264 and the corresponding STEP PDM modules on a particular example of product [45]. In order to formalise and verify the proposed mappings, we are proposing First Order Logic (FOL) patterns to define the semantics of each construct of the standards conceptual models, such as class, attribute, association and aggregations, generalization and hierarchies, derived from the "patterns of formalization" as proposed by [49] and extended by [53] and [54] .

FOL provides an objective solution to the above mentioned problems: FOL is a knowledge representation formalism which allows modelling the application domain by defining the relevant 
concepts of the domain itself, and then using these concepts to specify properties of objects and individuals occurring in the domain. FOL is a language characterized by a formal specification of the semantics that allows expressing structured knowledge in one hand and promotes the implementation of reasoning support in the other hand.

In our approach, each relationship between different concepts has been analysed, then setting semantic correspondences between them to compare the information embedded. In order to analyse the semantic relationships between concepts, informally defined in the standards, we choose FirstOrder-Logic (FOL) predicates: each predicate formalizes mappings between STEP PDM concepts and IEC 62264 ones, represented by a FOL axioms, thus providing an unambiguous representation of knowledge.

Table 1 lists the 9 patterns formalizing, in FOL, respectively the UML concepts of class, association, multiplicity, class association, aggregation, generalization, class hierarchy, disjointness, completeness.

Table 1 - Formalization in FOL of UML concepts [53] [54]

\begin{tabular}{|c|c|}
\hline$\forall x, y \cdot(C(x) \wedge a(x, y)) \supset T(y)$ & $1^{\circ}$ pattern: Class \\
\hline$\forall \mathrm{x}_{1}, \ldots, \mathrm{x}_{\mathrm{n}} \cdot \mathrm{A}\left(\mathrm{x}_{1}, \ldots, \mathrm{x}_{\mathrm{n}}\right) \supset \mathrm{C}_{1}\left(\mathrm{x}_{1}\right) \wedge \ldots \wedge \mathrm{C}_{\mathrm{n}}\left(\mathrm{x}_{\mathrm{n}}\right)$ & $\begin{array}{l}2^{\circ} \text { pattern: } \\
\text { Association }\end{array}$ \\
\hline $\begin{array}{l}\forall \mathrm{x} . \mathrm{C}_{1}(\mathrm{x}) \supset\left(\mathrm{m}_{1} \leq \#\{\mathrm{y} \mid \mathrm{A}(\mathrm{x}, \mathrm{y})\} \supset \mathrm{n}_{1}\right) \\
\forall \mathrm{x} . \mathrm{C}_{2}(\mathrm{x}) \supset\left(\mathrm{m}_{2} \leq \#\{\mathrm{y} \mid \mathrm{A}(\mathrm{x}, \mathrm{y})\} \supset \mathrm{n}_{2}\right)\end{array}$ & $\begin{array}{l}3^{\circ} \text { pattern: } \\
\text { Multiplicity }\end{array}$ \\
\hline $\begin{array}{c}\forall \mathrm{x}, \mathrm{y} \cdot \mathrm{A}(\mathrm{x}) \wedge \operatorname{ri}(\mathrm{x}, \mathrm{y}) \supset \mathrm{Ci}(\mathrm{y}), \text { for } \mathrm{i}=1, \ldots, \mathrm{n} \\
\forall \mathrm{x} . \mathrm{A}(\mathrm{x}) \supset \exists \mathrm{y} . \operatorname{ri}(\mathrm{x}, \mathrm{y}), \text { for } \mathrm{i}=1, \ldots, \mathrm{n} \\
\forall \mathrm{x}, \mathrm{y}, \mathrm{y}^{\prime} . \mathrm{A}(\mathrm{x}) \wedge \operatorname{ri}(\mathrm{x}, \mathrm{y}) \wedge \operatorname{ri}\left(\mathrm{x}, \mathrm{y}^{\prime}\right) \supset \mathrm{y}=\mathrm{y}^{\prime}, \text { for } \mathrm{i}=1, \ldots, \mathrm{n} \\
\forall y_{1}, \ldots, y_{n}, x, x^{\prime} . A(x) \wedge A\left(x^{\prime}\right) \wedge \Lambda_{i=1 \ldots \mathrm{n}}\left(r_{i}\left(x, y_{i}\right) \wedge r_{i}\left(x^{\prime}, y_{i}\right)\right) \supset x=x\end{array}$ & $\begin{array}{c}4^{\circ} \text { pattern: Class } \\
\text { Association }\end{array}$ \\
\hline$\forall x, y \cdot G(x, y) \supset C_{1}(x) \wedge C_{2}(y)$ & $\begin{array}{c}5^{\circ} \text { pattern: } \\
\text { Aggregation }\end{array}$ \\
\hline$\forall \mathrm{x} . \mathrm{C}_{1}(\mathrm{x}) \supset \mathrm{C}(\mathrm{x})$ & $\begin{array}{c}6^{\circ} \text { pattern: } \\
\text { Generalization }\end{array}$ \\
\hline$\forall \mathrm{x} . \mathrm{C}_{\mathrm{i}}(\mathrm{x}) \supset \mathrm{C}(\mathrm{x})$, for $\mathrm{i}=1, \ldots, \mathrm{n}$ & $\begin{array}{c}7^{\circ} \text { pattern: Class } \\
\text { Hierarchy }\end{array}$ \\
\hline$\forall \mathrm{x} . \mathrm{C}_{\mathrm{i}}(\mathrm{x}) \supset \Lambda_{\mathrm{j}=\mathrm{i}+1}^{\mathrm{n}} \neg \mathrm{C}_{\mathrm{j}}(\mathrm{x})$, for $\mathrm{i}=1, \ldots, \mathrm{n}-1$ & $\begin{array}{l}8^{\circ} \text { pattern: } \\
\text { Disjointness }\end{array}$ \\
\hline$\forall \mathrm{x} . \mathrm{C}(\mathrm{x}) \supset \mathrm{V}^{\mathrm{n}}{ }_{\mathrm{i}=1} \mathrm{Ci}(\mathrm{x})$ & $\begin{array}{l}9^{\circ} \text { pattern: } \\
\text { Completeness }\end{array}$ \\
\hline
\end{tabular}


The semantics of the modelling concepts of IEC 62264 and ISO 10303, informally defined in the standard, have been formalized by FOL axioms: on Table 2 and Table 3 it is possible to see some of the important FOL axioms of concepts in STEP PDM and IEC 62264 respectively.

\section{Table 2 - Formalization in FOL axioms of Product concept in STEP PDM}

\begin{tabular}{|l|}
$\forall \forall \mathrm{x}, \mathrm{y} .(\operatorname{Product}(x) \wedge \operatorname{Name}(\mathrm{x}, \mathrm{y})) \supset \operatorname{String}(\mathrm{y})$ \\
\hline$\forall \mathrm{x} . \operatorname{Product}(x) \supset(0 \leq \#\{y \mid \operatorname{Name}(x, y)\} \supset 1)$ \\
$\forall \mathrm{x}, \mathrm{y} .(\operatorname{Product}(x) \wedge \operatorname{Description}(\mathrm{x}, \mathrm{y})) \supset \operatorname{String}(\mathrm{y})$ \\
$\forall \mathrm{x} . \operatorname{Product}(x) \supset(0 \leq \#\{y \mid \operatorname{Description}(x, y)\} \supset 1)$ \\
\hline
\end{tabular}

Table 3 - Formalization in FOL axioms of Material Definition concept in IEC 62264

\begin{tabular}{|l|}
\hline$\forall \mathrm{x}, \mathrm{y}$. (MaterialDefinitionType $(x) \wedge$ Description $(\mathrm{x}, \mathrm{y})) \supset$ DescriptionType $(\mathrm{y})$ \\
\hline$\forall \mathrm{x}$. MaterialDefinitionType $(x) \supset(0 \leq \#\{y \mid$ Description $(x, y)\})$ \\
\hline$\forall \mathrm{x}_{1}, \mathrm{x}_{2}$. MaterialDefinition $\left(\mathrm{x}_{1}, \mathrm{x}_{2}\right) \supset$ MaterialSpecificationType $\left(\mathrm{x}_{1}\right) \wedge$ MaterialDefinitionType $\left(\mathrm{x}_{2}\right)$ \\
\hline$\forall \mathrm{x}_{1}$. MaterialSpecificationType $\left(\mathrm{x}_{1}\right) \supset\left(0 \leq \#\left\{y \mid\right.\right.$ MaterialDefinition $\left.\left.\left(\mathrm{x}_{1}, \mathrm{x}_{2}\right)\right\} \supset 1\right)$ \\
$\forall \forall \mathrm{x}_{2}$. MaterialDefinitionType $\left(\mathrm{x}_{2}\right) \supset\left(0 \leq \#\left\{y \mid\right.\right.$ MaterialDefinition $\left.\left.\left(\mathrm{x}_{1}, \mathrm{x}_{2}\right)\right\} \supset 1\right)$ \\
\hline
\end{tabular}

The FOL axioms serve to define the mapping between concepts of STEP PDM of ISO 10303 and IEC 62264 models (the Table 4 contains some of the obtained mapping rule).

Table 4 - Mapping rules

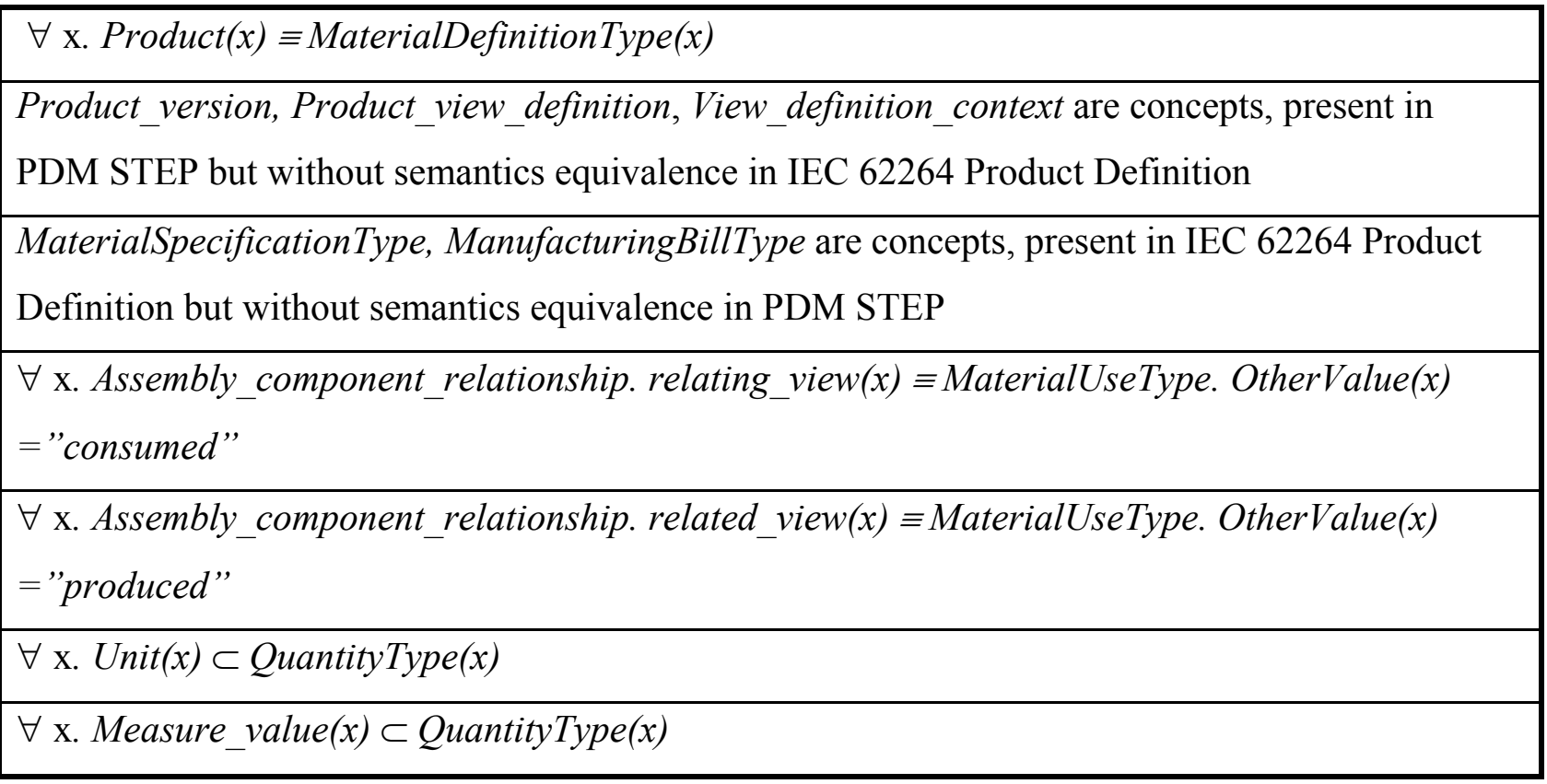


Taking into account the previous FOL axioms of standard models and the concepts mapping between them, the Product Ontology is proposed. Starting from the realization, demonstrated by mapping, that the IEC62264 models contain the information included in STEP PDM, we merge the specific information of STEP PDM in B2MML ontology, in order to build an ontological model that will be able to store all product technical data and information, consistent with both standards. In other words, STEP PDM will extend the IEC62264 ontology. This common model will be able to provide mappings from and to the enterprise applications with respect to product life cycle.

A deductive system is used to demonstrate, on a purely syntactic basis, that one formula is a logical consequence of another formula. A rule of inference states that, given a particular (or a set) of FOL axioms, another one can be derived as a logical conclusion. In this way it is easy integrating information, in a common model.

For example: if the following FOL axioms are true:

\begin{tabular}{|l|l|}
\hline$\forall$ x. Product $(x) \equiv$ MaterialDefinitionType $(x)$ & Mapping rule \\
\hline
\end{tabular}

\begin{tabular}{|c|c|}
\hline$\forall \mathrm{x}, \mathrm{y} .($ Product_version $(x) \wedge \operatorname{Description}(\mathrm{x}, \mathrm{y})) \supset \operatorname{String}(\mathrm{y})$ & \multirow{3}{*}{ FOL axioms of STEP PDM } \\
\hline$\forall \mathrm{x}$. Product_version $(x) \supset(0 \leq \#\{y \mid \operatorname{Description}(x, y)\} \supset 1)$ & \\
\hline$\forall \mathrm{x}_{1}, \mathrm{x}_{2}$. of_product $\left(\mathrm{x}_{1}, \mathrm{x}_{2}\right) \supset \operatorname{Product}\left(\mathrm{x}_{1}\right) \wedge \operatorname{Product}$ version $\left(\mathrm{x}_{2}\right)$ & \\
\hline
\end{tabular}

Then, the following axioms are true:

\begin{tabular}{|c|c|}
\hline$\forall \mathrm{x}, \mathrm{y} .\left(\operatorname{Product} \_\right.$version $\left.(x) \wedge \operatorname{Description}(\mathrm{x}, \mathrm{y})\right) \supset \operatorname{String}(\mathrm{y})$ & \\
\hline$\forall$ x. Product_version $(x) \supset(0 \leq \#\{y \mid \operatorname{Description}(x, y)\} \supset 1)$ & New FOL axioms of Product \\
\hline $\begin{array}{l}\forall \mathrm{x}_{1}, \quad \mathrm{x}_{2} . \text { of_product }\left(\mathrm{x}_{1}, \mathrm{x}_{2}\right) \supset \text { MaterialDefinitionType }\left(\mathrm{x}_{1}\right) \wedge \\
\text { Product_version }\left(\mathrm{x}_{2}\right)\end{array}$ & Ontology \\
\hline
\end{tabular}

For uniformity of language, we can rename Product_version as MaterialDefinitionVersionType, in such way:

\begin{tabular}{|c|c|}
\hline $\begin{array}{l}\forall \mathrm{x}, \mathrm{y} \cdot(\text { MaterialDefinitionVersionType }(x) \wedge \operatorname{Description}(\mathrm{x}, \mathrm{y})) \\
\supset \operatorname{String}(\mathrm{y})\end{array}$ & \\
\hline 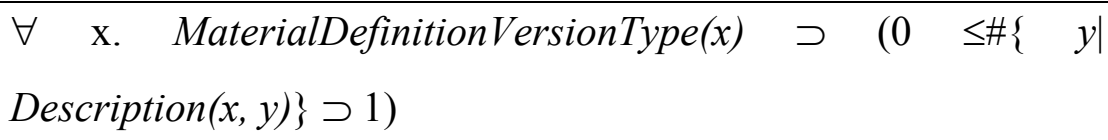 & $\begin{array}{l}\text { New FOL axioms of Product } \\
\text { Ontology }\end{array}$ \\
\hline $\begin{array}{l}\forall \mathrm{x}_{1}, \quad \mathrm{x}_{2} . \text { of_product }\left(\mathrm{x}_{1}, \mathrm{x}_{2}\right) \supset \text { MaterialDefinitionType }\left(\mathrm{x}_{1}\right) \wedge \\
\text { MaterialDefinitionVersionType }\left(\mathrm{x}_{2}\right)\end{array}$ & \\
\hline
\end{tabular}


This step allows integrating the concept "Product_version", specific in STEP PDM, in IEC 62264. Thus, our common ontological model of product information, supporting the information interoperability between manufacturing systems, maintains the traceability of product during its lifecycle. The whole ONTO-PDM product ontology is based on the 8 existing IEC62264 models (Product Definition, Material, Equipment, Personnel, Process Segment, Production Schedule, Production Capability, and Production Performance). Each of them is extended by STEP PDM concepts, including manufacturing constraints and mapping rules. An excerpt of the Product Ontology is shown in Figure 7.

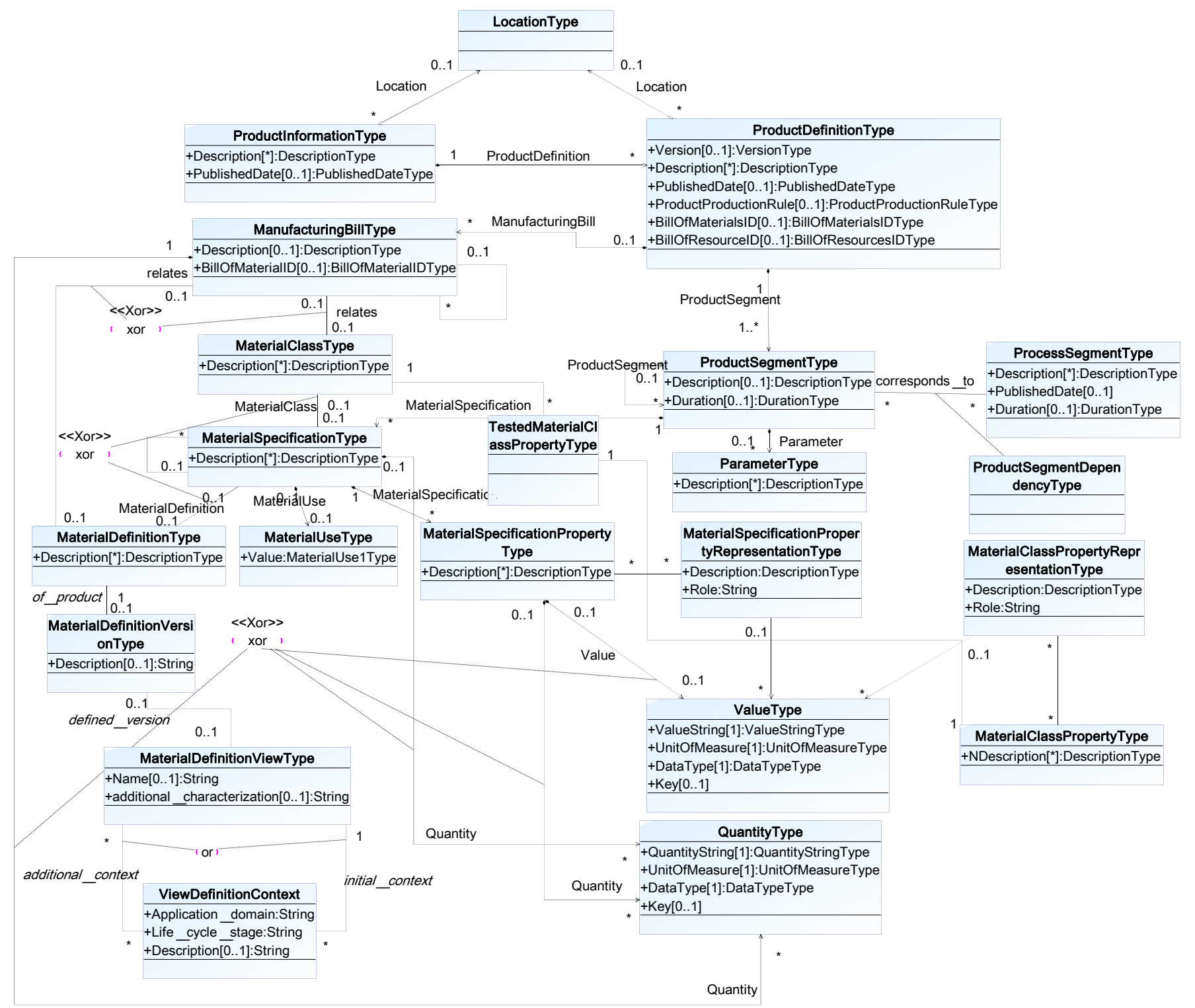

Figure 7 - An excerpt of the Product Ontology structure 
Finally the whole Product Ontology formalising the knowledge and skill embedded in products and the related semantics of concepts has been used for a test case providing a validation and demonstrating how it can support the interoperability between manufacturing applications.

\section{THE CASE STUDY}

The proposed case study concerns the simulation of distributed activities necessary to manufacture a simple product prototype. It was based on the assumption of two simulated manufacturing settings, one placed in Italy and the other in France. The product prototype was conceived and designed at the Department $(D I M e G)$ of the Politecnico di Bari, in Bari, Italy. The definition of product has been supposed driven by market or by customer requirements and forecasting. Technical and geometrical information, jointly with business information, such as the required quantity of pieces, are stored in a memory chip (a RFID), and structured in the information model that implements the Product Ontology.

This digital product specification in the simulation was sent to the Atelier Inter-Établissements de Productique Lorrain (AIPL-PRIMECA) of the University of Lorraine, France for manufacturing the product on the base of information drawn from the Product Ontology, supposed to be retrieved from a memory support embedded into the product.

At the end of production process, the manufactured product was sent to DiMeG for the delivery to the customer.

Each manufacturing setting was equipped with its enterprise systems (i.e. Windchill PDM, ProEngineer CAD and SAP R/3 for DiMeG or Flexnet MES and Sage ERP X3 for AIPL), dedicated to specific tasks (engineering tasks or manufacturing ones) and provided by a particular vendor. In this product-centric information system, these heterogeneous applications were forced to interoperate with the product, to store and to draw the pertinent product information on it.

Actually, the exchange of information between enterprise systems defines a sort of "applicationdriven interoperability", represented by the sequence diagram in Figure 8. In this figure, the sequence chart represent the many exchange of messages that take place between each enterprise systems from the "customer order" sent to the SAP R/3 ERP to the final "delivery note" sent back to the customer. This scenario shows the complex information flows between all enterprise applications that belong to each manufacturing, transportation and selling facilities. 


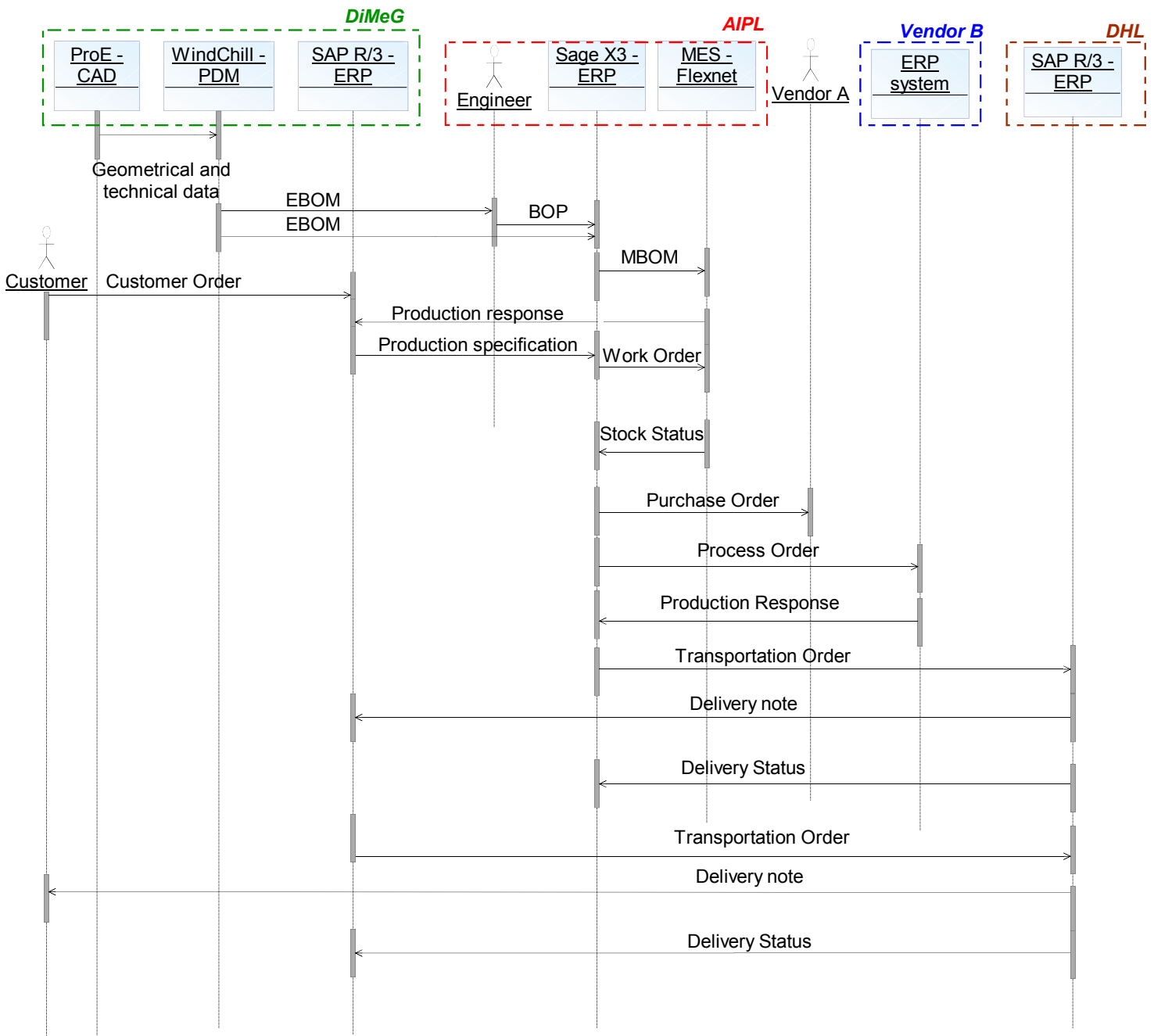

Figure 8 - Application driven interoperability scenario

The Product Ontology built was capable to support the information exchange between the product and the many applications that interact with him, thus figuring a "product-centric" scenario, as shown by the sequence diagram in Figure 9. In such "product-centric" scenario, the figure shows that all information flows are centralised to the product ontology that acts, then, as a mediator between all involved enterprise systems. 


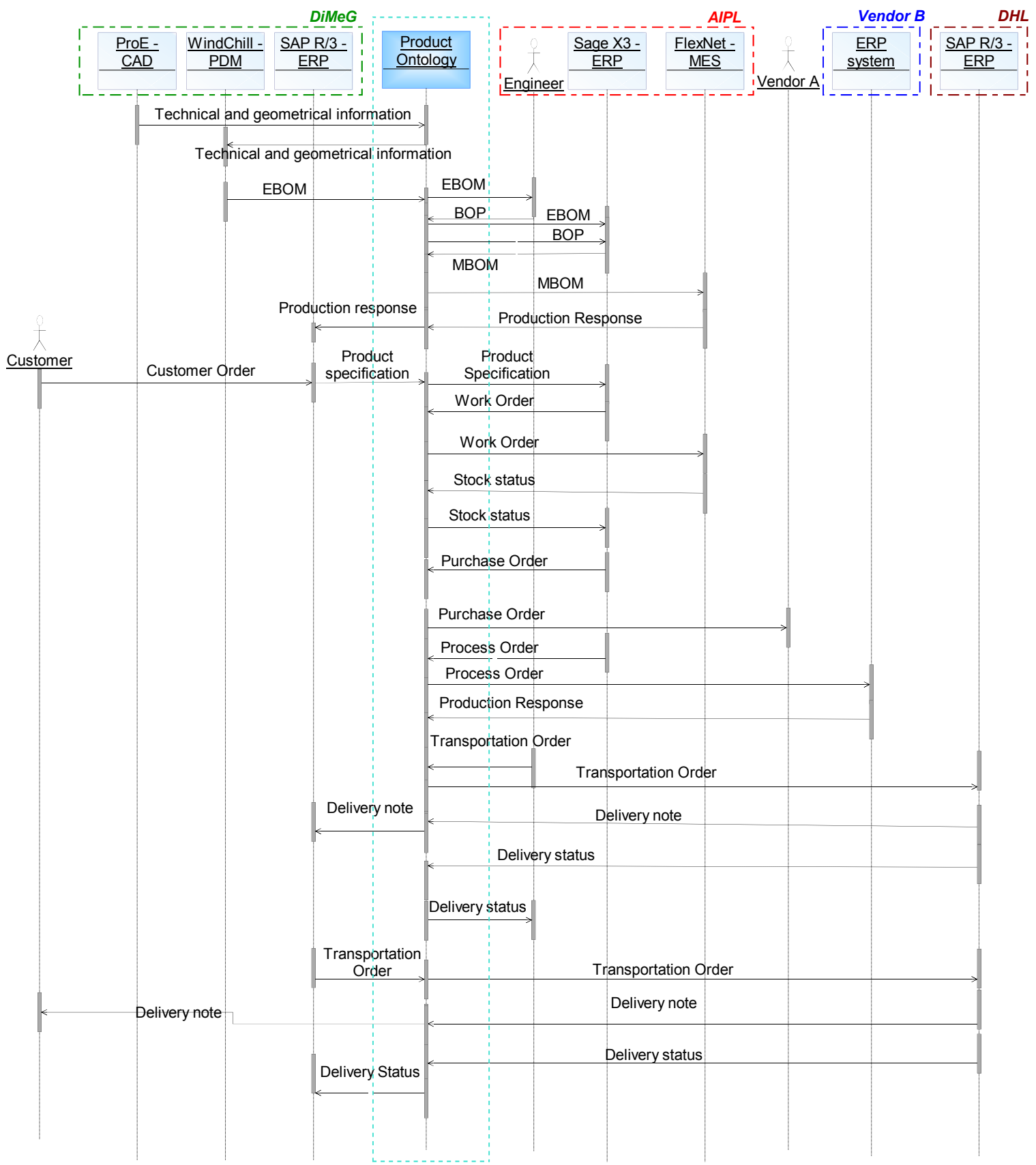

Figure 9 - Product-centric interoperability scenario

For the sake of simplicity, we here focus on a single part of one of the AIPL products, the P09 product (Figure 9), providing the description of its production and the implementation of the reference-information model; this is intended to show the level of interoperability possible between the Product Ontology itself and the applications that interact with it. 

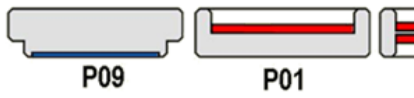

01

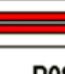

P08

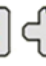

08

P11

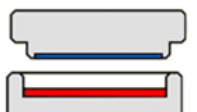

Product 01,09
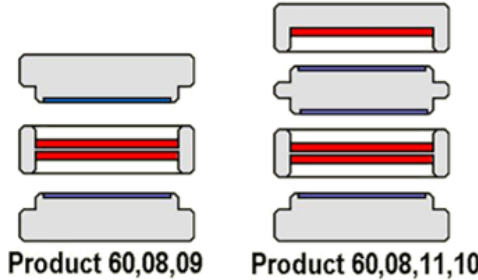

Figure 10 - Parts and some products produced at the AIPL

Each phase of production process has been implemented in the model: from the design of Engineering Bill Of Materials of P09 at DiMeG up to the realization of Manufacturing Bill-ofMaterial (MBOM) at AIPL (Figure 10), from the customer requirement to the supplier, from subcontract work and production of P09 up to the delivery of P09 to the customer. All information exchanged during the P09 lifecycle is stored in and retrieved from the Product Ontology (see Figure 11-12-13). The purpose of these figures is to demonstrate how the product ontology built with our methodology is able to store any information related to a product (or a component) in a generic and consistent way. Figure 11 shows the instantiation of the product ontology, storing all information related to the one of the component of the product, a galvanized disc. Figure 12 represents all information related to the manufacturing process needed to produce the galvanized disc while Figure 13 specifies the scheduling of the cutting process related to the same component. 


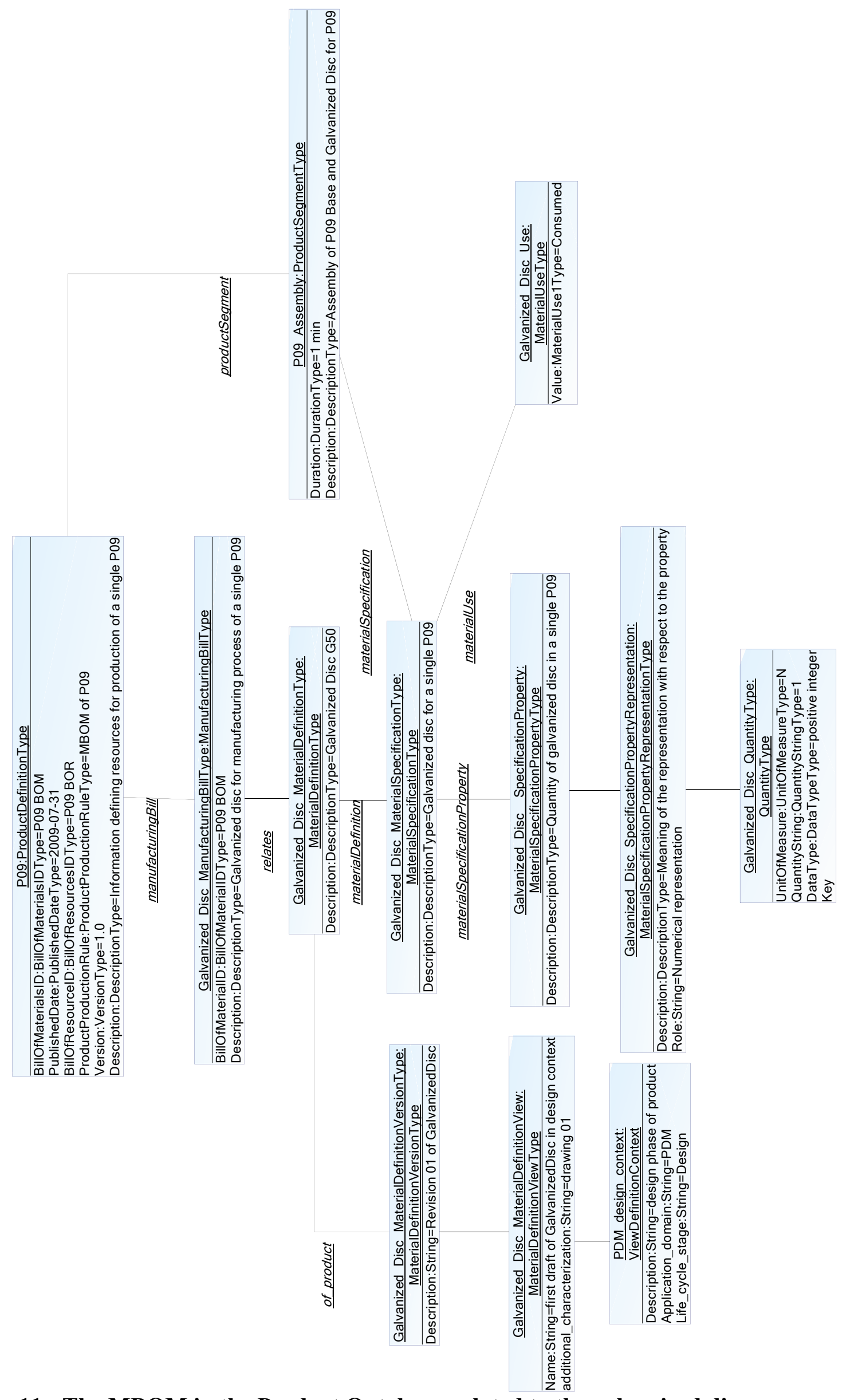

Figure 11 - The MBOM in the Product Ontology, related to the galvanized disc 

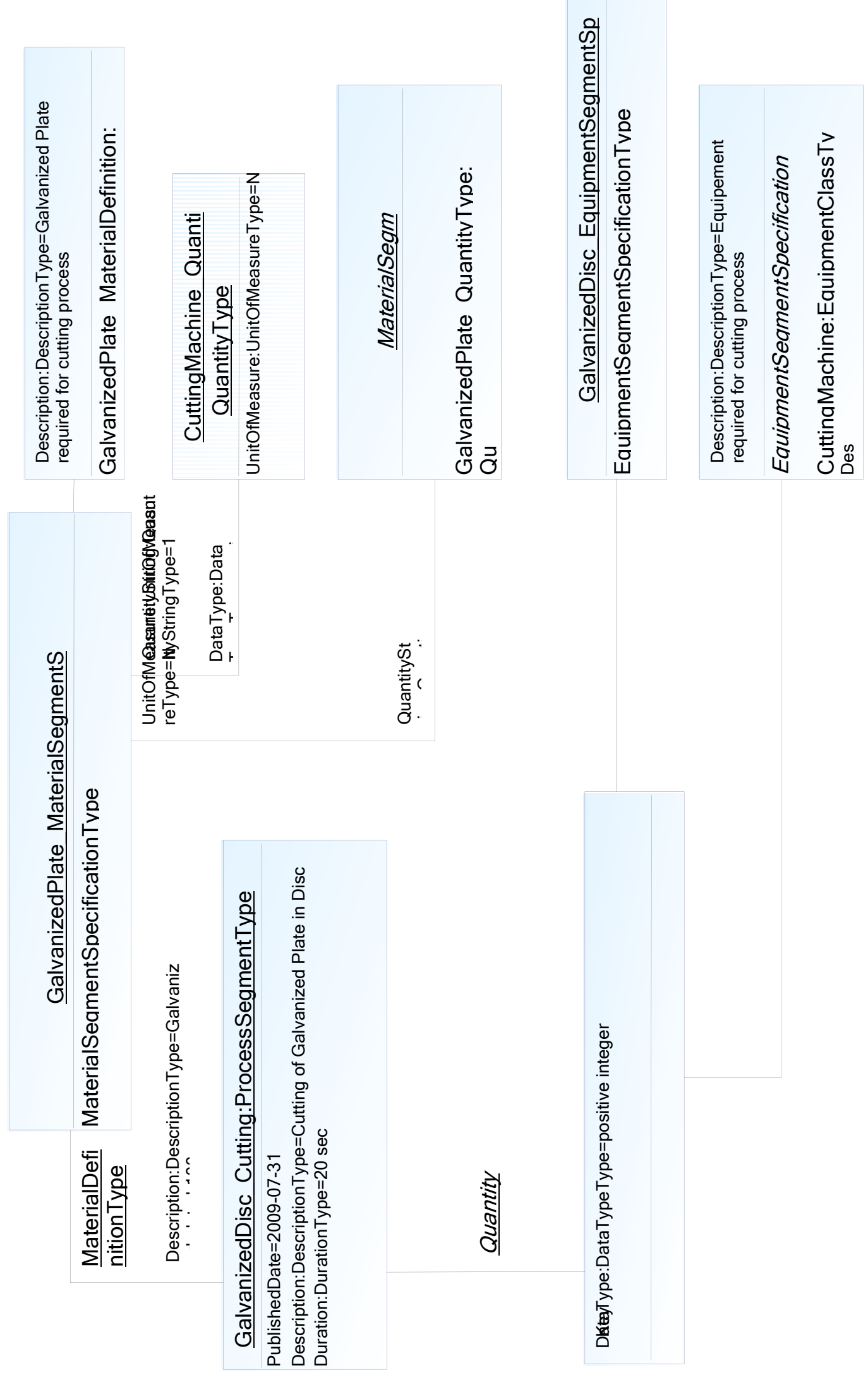

Figure 12 - The information about galvanized disc cutting process in the Product Ontology (materials and equipment) 


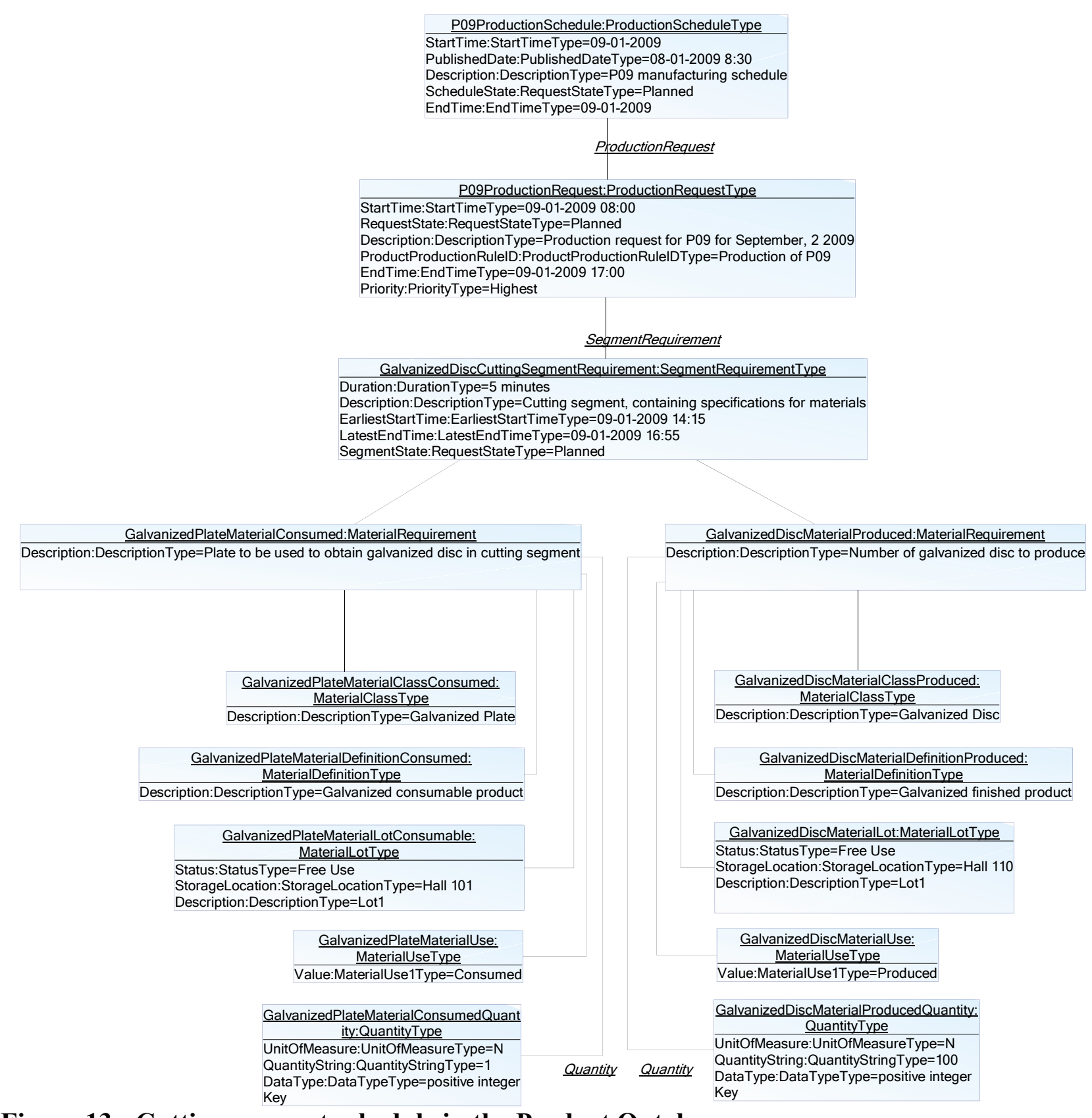

Figure 13 - Cutting segment schedule in the Product Ontology

\section{CONCLUSIONS AND FUTURE RESEARCH}

This paper provides a new approach focused on the concept of product as a pivotal element: the product implicitly embeds the information about itself, referring to a so-called ONTO-PDM "Product Ontology". This means that it potentially allows the information exchange between the systems that interact with it by minimizing semantic uncertainty. The potential main advantages of the proposed approach are the pertinence of the information structure, the expressivity of the information and the traceability of product technical data. The implementation of the ontology has 
been done through (1) its translation into the OWL language [55] for its use with the Protégé ${ }^{1}$ ontology development and instantiation environment and (2) its translation into an Entity/Relationship model for its implementation into a DBMS.

A limitation in the research reported is related to the two selected standards. Indeed, if more standards need to be considered to extend the ontology, the current manual mapping process would represent a major effort [37].

Future research developments can be suggested to complement this work:

i) to consider other standardisation initiatives in order to have a more complete model,

ii) to develop a suitable storing technology in order to embed products information structure directly on the product itself. Technologies such as RFID and MEMS may be candidate solutions,

iii) to develop standard interfaces that link the specific product model views to exiting enterprise applications,

iv) finally, to propose the standardization of the Product Ontology.

\section{AKNOWLEDGEMENT}

This research was developed under the umbrella of the common agreement between DIMEG Politecnico di Bari (Italy) and CRAN - Université Henri Poincaré - Nancy I (France) within the INTEROP V-Lab network, an official virtual laboratory settled in 2008 and officially approved by E.C. The work presented in this paper was partially supported by the program for scientific cooperation between France and Italy PHC GALILEO, project No 25974QF (2011).

\section{REFERENCES}

[1] J. Lee, Chae H., C.-H. Kim, K. Kim, Design of product ontology architecture for collaborative enterprise, Expert Systems with Applications. 36 (2009) 2300-2309.

[2] H. Panetto, Towards a Classification Framework for Interoperability of Enterprise Applications, International Journal of CIM. 20/8 (2007) 727-740, Taylor \& Francis, December, ISSN: 0951-192X [3] J. Jiao, T. W. Simpson, Z. Siddique, Product family design and platform-based product development: a state-of-the-art review, Journal of Intelligent Manufacturing. 18 (2007) 5-29

\footnotetext{
${ }^{1}$ http://protege.stanford.edu
} 
[4] D. M. Gimémez, M. Vegetti, H. P. Leone, G. P. Henning, PRoduct ONTOlogy: Defining product-related concepts for logistics planning activities, Computers in Industry. 59/2-3 (2007) 231241

[5] Guarino, N. (Ed.) Formal Ontology in Information Systems, 1998. IOS Press.

[6] A. Tursi, Ontology-based approach for enterprise production systems interoperability, $\mathrm{PhD}$ dissertation, University Henri Poincaré Nancy I and Politecnico di Bari, November 2009

[7] R. Colomb, Ontology and the Semantic Web, IOS Press, Amsterdam, 2007. ISBN 978-1-58603729-1.

[8] B. Kapoor, S. Sharma, A Comparative Study Ontology Building Tools for Semantic Web Applications, International journal of Web \& Semantic Technology. 1/3 (2010) 1-13.

[9] S. B. Yoo, Y. Kim, Web-based knowledge management for sharing product data in virtual enterprises, International Journal of Production Economics. 75 (2002) 173-183

[10] T. Berners-Lee, J. Hendler, O. Lassila, The Semantic Web, Scientific American, May 2001.

[11] M. Vegetti, G. P. Henning, H. P. Leone, PRoduct ONTOlogy. An ontology for complex product modelling domain, Proceedings of the ENPROMER, Rio de Janeiro, 2005.

[12] S. Fenves, S. Foufou, C. Bock, N. Bouillon, R. D. Sriram, CPM2: A Revised Core Product Model for Representing Design Information. National Institute of Standards and Technology, NISTIR 7185, Gaithersburg, MD 20899, USA, 2004.

[13] R. Barbau, S. Krima, X. Fiorentini, R. Sudarsan, A. Narayanan, S. Foufou, R. D. Sriram, OntoSTEP: Enriching product model data using ontologies. NIST (access through http://www.nist.gov/manuscript-publication-search.cfm?pub_id=906151 on 30.1.2011)

[14] S. Krima, R. Barbau, X. Fiorentini, R. Sudarsan, S. Foufou, R. D. Sriram, OntoSTEP: OWLDL Ontology for STEP, Proceedings of the 6th International Conference on Product Lifecycle Management Location: Bath, July 6-8, 2009

[15] ISO 18629-1:2004, Industrial automation systems and integration -- Process specification language -- Part 1: Overview and basic principles. Geneva, 2004

[16] L. Patil, D. Dutta, R. Sriram, Ontology-based exchange of product data semantics, IEEE Transactions of Automation Science and Engineering. 2 (2005) 213-225.

[17] S. Fenves, S. Foufou, C. Bock, R. D. Sriram, CPM2: A Core Model for Product Data, Journal of Computing and Information Science in Engineering. 8/1 (2008) 14501-14507 [18] S. Rachuri, M. M. Baysal, U. Roy, S. Foufou, C. Bock, S. Fenves, E. Subrahmanian, K. Lyons, R. D. Sriram, Information Models for Product Representation: Core and Assembly Models, International Journal of Product Development. 2/3 (2005) 207-235 
[19] S. Fenves, R. D. Sriram, S. Rachuri, F. Wang, A product information modelling framework for product lifecycle management. Proceedings of the international symposium on product lifecycle management. June 01, 2003

[20] W. Kim, D. W. Choi, S. Park, Agent based intelligent search framework for product information using ontology mapping, Journal of Intelligent Information Systems. 30/3 (2008) 227247. Springer

[21] M. Guo, S. Li, J. Dong, X. Fu, Y. Hu, Q. Yin, Ontology-based product data integration, Proc. 17th International Conference on Advanced Information Networking and Applications; ISBN 07695-1906-7, 530-533. 2003

[22] C. Dartigues, Product data exchange in a cooperative environment. Ph.D. dissertation, University of Lyon 1 (in french). 2003

[23] C. Dartigues, P. Ghodous, M. Gruninger, D. Pallez, R. Sriram, CAD/CAPP Integration using Feature Ontology, Concurrent Engineering. 15/2 (2007) 237-249

[24] M. R. Genesereth, R. E. Fikes, Knowledge Interchange Format, Version 3.0 Reference Manual. Technical Report Logic-92-1, Computer Science Department, Stanford University. 1992

[25] H. B. Jun, D. Kiritsis, Research issues on closed-loop PLM, Computers in Industry. 58/8-9 (2007) 866-868

[26] S. Terzi, Elements of Product Lifecycle Management: Definitions, Open Issues and Reference Models. PhD dissertation - University Henri Poincaré Nancy I and Politecnico di Milano, May 2005 [27] S. Terzi, H. Panetto, G. Morel, M. Garetti, A holonic metamodel for product lifecycle management, International Journal of Product Lifecycle Management. 2/3 (2007) 253-289, Inderscience, December, ISBN 1743-5110

[28] A. Matsokis, D. Kiritsis, An ontology-based approach for Product Lifecycle Management, Computers in Industry. 61/8 (2010) 787-797

[29] J. Cassina, S. Terzi, H. Panetto, M. Taisch, Development of an holonic metamodel for lifecycle support and product extension, 11th International Conference on Concurrent Enterprising (ICE05), University BW Munich, Germany, 2005 20-22 June, ISBN 0-85358-128-2

[30] H. Kühnle (Editor), Distributed Manufacturing: Paradigm, Concepts, Solutions and Examples. XXII, 191 p., 2010. Springer. ISBN: 978-1-84882-706-6

[31] C. Bock, X. Zha, H. Suh, J.-H. Lee, Ontological product modelling for collaborative design, Advanced Engineering Informatics. 24 (2010) 510-524

[32] Y.-J. Chen, Y.-M. Chen, H.-C. Chu, Development of a mechanism for ontology-based product lifecycle knowledge integration, Expert Systems with Applications. 36 (2009) 2759-2779 
[33] Y. Jiang, G. Peng, W. Liu, Research on ontology-based integration of product knowledge for collaborative manufacturing, The International Journal of Advanced Manufacturing Technology. 49/9 (2010) 1209-1221

[34] L. F. Lin, W. Y. Zhang, Y. C. Lou, C. Y. Chu, M. Cai M, Developing manufacturing ontologies for knowledge reuse in distributed manufacturing environment, International Journal of Production Research. 49/2 (2011) 343 - 359, Taylor and Francis

[35] J. Lee, S. Fenves, C. Bock, H. Suh, R. Sudarsan, X. Fiorentini, R. D. Sriram, Product Modelling Framework and Language for Behaviour Evaluation, Proceedings of the 6th Annual IEEE Conference on Automation Science and Engineering (IEEE CASE), Toronto, August 21-24, 2010

[36] J. Cho, S. Han, H. Kim, Meta-ontology for automated information integration of parts libraries, Computer-Aided Design. 38/7 (2006) 713-725.

[37] H. K. Lin, J. A. Harding, A manufacturing system engineering ontology model on the semantic web for inter-enterprise collaboration, Computers In Industry. 58/5 (2007) 428-437 [38] S. C. Lim, Y. Liu, W. B. Lee, Multi-facet product information search and retrieval using semantically annotated product family ontology, Information Processing \& Management. 46/4 (2009) 479-493.

[39] S. C. Lim, Y. Liu, W. B. Lee, A Methodology for Building a Semantically Annotated Multifaceted Ontology for Product Family Modelling, Advanced Engineering Informatics. 25/2 (2010) $147-161$

[40] I. R. Grosse, J. M. Milton-Benoit, J. C. Wileden, Ontologies for supporting engineering analysis models, Artificial Intelligence for Engineering Design, Analysis and Manufacturing. 19/1 (2005) 1-18.

[41] S. Ahmed, S. Kim, K. M. Wallace, A Methodology for Creating Ontologies for Engineering Design, Journal of Computing and Information Science in Engineering. 7/2 (2007) 132-140.

[42] L. Taehee, L. Ig-hoon, L. Suekyung, L. Sang-goo, K. Dongkyu, C. Jonghoon, L. Hyunja, S. Junho, Building an operational product ontology system, Electronic Commerce Research and Applications Journal. 5/1 (2006) 16-28, Elsevier

[43] ISO/TS 10303 STEP modules related to Product Data Management. Industrial automation systems and integration - Product data representation and exchange, 2004, Geneva.

[44] IEC 62264 Enterprise-control system integration, Part 1. Models and terminology, Part 2: Model object attributes. ISO/IEC, 2002, Geneva. 
[45] A. Tursi, H. Panetto, G. Morel, M. Dassisti, Ontological approach for Products-Centric Information System Interoperability in Networked Manufacturing Enterprises, IFAC Annual Reviews in Control. 33/2 (2009) 238-245, December, Elsevier, ISSN: 1367-5788

[46] M. Dassisti, H. Panetto, A. Tursi, Product-driven Enterprise Interoperability for Manufacturing Systems Integration, Proceedings of the BPM2006 Business Process Management Workshops. 2nd ENEI Workshop, Vienna, Austria, September 2006, LNCS 4103, 249-260. Springer Verlag

[47] G. Morel, H. Panetto, M. B. Zaremba, F. Mayer, Manufacturing Enterprise Control and Management System Engineering: paradigms and open issues, IFAC Annual Reviews in Control. 27/2 (2003) 199-209, Elsevier

[48] M. Kärkkäinen, T. Ala-Risku, K. Främling, The product centric approach: a solution to supply network information management problems?, Computers in Industry. 52/2 (2003) 147-159.

[49] R. van Der Straeten, T. Mens, J. Simmonds, V. Jonckers, Using Description Logic to Maintain Consistency between UML Models. The Unified Modeling Language. Modeling Languages and Applications (UML 2003). Lecture Notes in Computer Science, LNCS 2863, (2003) 326-340

[50] T. R. Gruber, Toward principles for the design of ontologies used for knowledge sharing. In Formal Ontology in Conceptual Analysis and Knowledge Representation (N. Guarino and R. Poli, eds.), 1993. Kluwer Academic Publishers

[51] X. Fiorentini, R. Sudarsan, S. Ray, R. D. Sriram, Towards a Method for Harmonizing Information Standards, Proceedings of the fifth annual IEEE Conference on Automation Science and Engineering (IEEE CASE 2009); Bangalore, August 22-25, 2009

[52] H. C. Xu, X. F. Xu, T. He, Research on Transformation Engineering BOM into Manufacturing BOM Based on BOP, Applied Mechanics and Materials. Special issue on e-Engineering \& Digital Enterprise Technology. 10-12 (2008) 99-103

[53] D. Berardi, D. Calvanese, G. De Giacomo, Reasoning on UML class diagrams, Artificial Intelligence. 168/1-2 (2005) 70-118.

[54] D. Calvanese, G. De Giacomo, M. Lenzerini, Description logics for information integration. Computational Logic: From Logic Programming into the Future, Lecture Notes in Computer Science. 2408 (2002) 41-60. Springer Verlag

[55] R. Gronmo, M. C. Jaeger, H. Hoff, Transformations Between UML and OWL-S. Model Driven Architecture: Foundations and Applications, Lecture Notes in Computer Science, LNCS 3748 (2005) 269-283 